\title{
Patient-reported outcomes of ocriplasmin for the treatment of vitreomacular traction: a systematic review and synthesis of the literature
}

This article was published in the following Dove Medical Press journal:

Patient Related Outcome Measures

\author{
Benedicte Lescrauwaet ${ }^{1}$ \\ Koenraad Blot ${ }^{2}$ \\ Timothy L Jackson ${ }^{3}$ \\ 'Xintera, Outcomes Research, Ghent, \\ Belgium; '2Xintera, Ghent, Belgium; \\ ${ }^{3}$ Life Sciences and Medicine, King's \\ College London, Department of \\ Ophthalmology, King's College \\ Hospital, London, UK
}

Purpose: Vitreomacular traction (VMT) is a disease in which the vitreous exerts abnormally strong traction on the macula, the area of the eye responsible for detailed central vision. If this traction significantly distorts the macula then VMT can lead to troublesome distorted vision (metamorphopsia), sometimes occurring despite relatively preserved visual acuity. Ocriplasmin, administered as a single intravitreal injection, aims to release VMT and improve vision. While the effect of ocriplasmin on traction release and visual acuity is well characterized, the effect of symptoms like metamorphopsia is not.

Methods: A systematic review and synthesis of the literature on patient reported outcomes (PRO) in relation to the use of ocriplasmin for the treatment of VMT was undertaken using MEDLINE and Embase databases, and the Cochrane central register of controlled trials (CENTRAL). Results: The review identified PRO data from 870 patients across three randomized controlled trials. The most commonly reported PROs were the 25-item National Eye Institute Visual Function Questionnaire (VFQ-25), a broad measure of vision-related quality of life, and Visual Function Response (VFR), an outcome combining quality of life and visual acuity outcomes. Treatment with ocriplasmin produced significant patient benefit vs control (sham or placeboinjection). Ocriplasmin was associated with a higher proportion of patients experiencing a clinically meaningful improvement in visual functioning with a difference of $11.8 \%$ for VFQ-25 and $23.2 \%$ for VFR responder analyses, respectively.

Conclusion: Patients with VMT have material impairment in visual functioning and quality of life, relative to their reduction in visual acuity. Ocriplasmin results in a significant improvement in visual functioning. Future research could include the development of new PROs specific to VMT. Keywords: macular hole, metamorphopsia, patient reported outcomes, symptomatic vitreomacular adhesion, vitreomacular traction, visual function questionnaire

\section{Plain language summary}

Why was this study done? Most trials of new eye treatments rely on visual acuity eye charts to measure treatment success, but for some conditions eye charts fail to fully capture patients' symptoms. This is particularly true for vitreomacular traction (VMT), a condition in which the watery gel inside the eye pulls on, and thereby damages, the light-receiving cells inside the back of the eye. Anatomic outcomes are therefore often used instead, but these are only a proxy for visual function. Patient reported outcomes (PRO) comprise patient questionnaires that may better capture the effects of VMT, and help quantify the effect of novel treatments.

What did the researchers do and find? We systematically surveyed and brought together the medical literature on a new treatment for VMT, ocriplasmin. Ocriplasmin is a drug that is injected into the eye. It aims to dissolve the vitreous and resolve VMT. We aimed to summarize the PROs following ocriplasmin treatment, in comparison to placebo/simulated treatment. We limited our
Correspondence: Benedicte Lescrauwaet Xintera, Outcomes Research, Gaston Crommenlaan 4/50I, Ghent 9050 , Belgium

Tel +32 47284638 I

Email benedicte.lescrauwaet@xintera. com 
analysis to high quality clinical trials. We found that ocriplasmin resulted in better PRO than placebo/simulated treatment.

What do these results mean? PROs may offer insight into clinical benefits that are better aligned to patient experience than visual acuity or anatomic success.

\section{Introduction}

Vitreomacular traction (VMT), also called symptomatic vitreomacular adhesion, is a disorder of the vitreoretinal interface in which abnormal vitreous traction pulls on the macula, the light-sensitive layer of the eye that is responsible for fine central vision such as reading and driving. VMT occurs in the context of an incomplete posterior vitreous detachment, where persisting macular adhesion leads to distortion of the macular architecture. ${ }^{1,2}$ There is a wide spectrum of severity and clinical findings. Some patients have minimal symptoms, while others are bothered by decreased or distorted central vision and alteration in image size. ${ }^{3-5}$ Progressive traction can lead to the development of a hole in the macula and worsening visual function. ${ }^{6-8}$

In clinical practice and clinical trials, the most commonly used measure of visual function is visual acuity (VA), established using eye charts. VA is effective at quantifying clear vs blurred vision, however it does not capture the entirety of visual disturbances in VMT. ${ }^{9} 10$ For example, most patients in large clinical trials of VMT presented with relatively good VA. ${ }^{11,12}$ By contrast, metamorphopsia or distorted vision was found to be highly prevalent in patients with VMT, but is typically not measured in clinical practice because of lack of widely accepted clinical tools to identify and quantify the degree of distortion. ${ }^{13}$

There are three commonly used management options for VMT - observation, vitreolysis and vitrectomy. There are also small clinical case series investigating the use of a gas bubble to treat VMT. ${ }^{14}$ The current standard of care in early stage VMT is observation, a strategy that is often justified for people with no or few symptoms and in the expectation that some cases may resolve spontaneously. However, more severe VMT, and most macular holes, justify the potential risks of surgical intervention, namely pars plana vitrectomy. ${ }^{15}$ Vitrectomy removes the vitreous and thereby the vitreomacular traction. Ocriplasmin is the only licensed pharmacological treatment for VMT. ${ }^{11}$ Ocriplasmin is an enzyme that is injected directly into the vitreous, wherein it is designed to dissolve vitreous and release vitreomacular adhesion. ${ }^{16}$

Given the shortcomings of VA as an outcome measure, anatomic success (release of VMT and macular hole closure) is often used instead. Indeed, vitreomacular adhesion release at day 28 was the primary outcome measure in the registration studies. ${ }^{11}$ This occurs in the expectation that visual symptoms will improve as the anatomical integrity of the vitreoretinal interface is restored. ${ }^{17,18}$ Nonetheless, anatomic success remains a proxy of visual function.

When clinical outcome measures fail to capture the impact of ophthalmic disease on a patient's life, patient reported outcomes (PROs) may address the deficit in the clinician's knowledge. ${ }^{5}$ A PRO describes any report or measure of the patient's health that comes directly from the patient without interpretation by a clinician or a researcher. ${ }^{19}$ PRO instruments were initially intended to supplement the physiological measures to better understand treatment effectiveness. ${ }^{20} \mathrm{In}$ ophthalmology a vast number of PRO instruments have been developed to assess the patient's perspective of the disease impact and treatment outcomes, however only a few retinaspecific disease instruments exist. ${ }^{20}$ The objective of this paper is to summarize, and where possible synthesize, the PROs relating to the use of ocriplasmin for the treatment of VMT.

\section{Materials and methods Study design and criteria for considering studies}

We undertook a systematic literature review to identify relevant clinical data. We included studies meeting the following PICOS criteria:

Participants: patients with a diagnosis of symptomatic vitreomacular adhesion (VMA), including VMT and macular holes.

Intervention: treatment with an intravitreal injection of ocriplasmin.

Comparator: the intended control was natural history, intravitreal placebo, sham or gas injection.

Outcomes: patient-reported outcomes.

Study design: to maximize PRO data, randomized controlled trials (RCTs), prospective, retrospective, controlled and uncontrolled studies were eligible.

The study protocol was registered with the international prospective register of systematic reviews (2018: CRD42018109567, National Institute of Health Research Center for Reviews and Dissemination, University of York, UK) and conducted in accordance with Preferred Reporting Items for Systematic reviews and Meta-analyses (PRISMA) guidance (http:// www.prisma-statement.org/, accessed May 27, 2018)

Inclusion criteria were as follows: studies of VMT or small to medium full thickness macular hole $(\mathrm{FTMH})(\leq 400$ $\mu \mathrm{m}$ in diameter) $;^{1}$ any PRO outcome reported. 
Exclusion criteria included articles appearing as abstract only, animal studies, case reports, studies with fewer than 12 subjects per arm, safety or clinical only reviews, editorials, commentary, and expert opinions.

\section{Search strategy and information sources}

We searched PubMed MEDLINE, Elsevier Embase databases and the Cochrane central register of controlled trials (CENTRAL) from inception date to October 3, 2018. In the absence of a validated methodological filter for identifying PRO and patient perspective studies a quality of life (QoL) search filter developed by Paisley et al was applied to identify PRO articles of interest. ${ }^{21,22}$ This QoL filter was further expanded by adding search terms for disease specific QoL instruments. The search strategy included the following search terms or keywords: quality of life; health-related QoL; quality adjusted life year; health state; health status; healthy years equivalents; life quality; utilities; wellbeing; short form 36 (SF-36); short form 12 (SF-12); Euroqol; eq 5d; quality of wellbeing scale; health utilities index (HUI or HUI-3); medical outcomes survey; visual function questionnaire; VFQ; NEI VFQ; CatQuest; MacDQoL; time trade-off; standard gamble; willingness to pay; patient preferences; patient perspectives; utility index; vision bolt-on item; patient reported outcome; functional outcomes; patient outcomes; visual function; visual function 14 score. Full details on the PRO search strategy are presented in Table S1. These PRO terms were combined using Boolean operators with the search term for the intervention (microplasmin, ocriplasmin or JETREA) and disease (vitreomacular adhesion or traction).

\section{Study selection}

One reviewer (BL) assessed the records identified by the searches and classified each record as either 1) possibly relevant or 2) definitely not relevant. Full-text copies of all possibly relevant records were obtained, and one reviewer (BL) classified them as either 1) definitely include, 2) unsure or 3) definitely exclude based on the criteria for inclusion. Discrepancies in eligibility were resolved by consensus following discussion (BL, TJ). Excluded records were documented.

\section{Data extraction strategy}

Relevant data from selected articles were extracted and summarized by a first reviewer (BL) and a second reviewer (TJ) verified the abstracted data against full text. For all eligible articles, the following data were abstracted: author; year of publication; title; source; study objective(s); location(s). The data items on study characteristics included: participants: country, total number of participants, age, sex, inclusion and exclusion criteria; Intervention and comparator details; PRO measure: type and definition, PRO outcomes as measured and reported in the study; study design; length of follow-up; and years in which the study was conducted. All reviewers evaluated the articles and confirmed the inclusion of selected articles for this review. The information included for each article was reviewed by the reviewers to ensure congruence of information extracted. Any discrepancy was resolved by consensus between reviewers and documented in the review.

\section{Assessment of risk of bias in included studies and heterogeneity among studies}

Included studies were assessed for bias using the methods and grades described in the Cochrane Handbook for Systematic Reviews of Interventions. If applicable, heterogeneity among studies was assessed using an $\mathrm{I}^{2}$ value $(>50 \%)$ to assess if variability in effect was due to sampling error. Diversity among studies was assessed by reviewing participant characteristics and trial methodology.

\section{Data synthesis and analysis}

Currently, there is no PRO measure that has been validated (testing of psychometric properties) specifically for use in a VMT population to assess the overall impact of the eye disorder on self-reported functional vision. ${ }^{23}$

The use of composite PRO measures has been favored as the morbidity associated with VMT is multifaceted. These composite endpoints traditionally included the VFQ-25 which measures dimensions of patient-reported visiontargeted health status that are thought to be most important to people with eye disease. Improvement in the VFQ-25 is evaluated using 12 subscale scores and a global composite score with higher scores indicating better health status. ${ }^{24,25}$ More recently, another composite PRO was developed using principal component analysis (PCA), to comprehensively evaluate changes in vision-related functioning as experienced by patients. ${ }^{26} \mathrm{~A}$ PCA reduces a multidimensional response into a restricted set of responses, called principal components, in an objective way while preserving as much of the overall variability in the multidimensional response as possible. ${ }^{27} \mathrm{~A}$ visual function response (composed of the first three dimensions of visual functioning according to PCA) was defined such that participants could be classified as responders or non-responders. Because PRO data may be assessed or analyzed using different analytical approaches, 
authors and/or sponsors were contacted to obtain unpublished data where necessary.

\section{Iterative changes to the study protocol}

As the systematic literature review identified PRO data from the ocriplasmin randomized clinical studies only, a quantitative pooled analysis of PRO results restricted to RCTs was added post hoc, with the measure of treatment effect being the proportion of responders for the PRO outcome. Risk difference and 95\%CI between groups were based on the percentage of responses. To increase the statistical power of the analysis compared to the individual studies, PRO data were pooled across all studies using study means. For combined studies, we pooled risk differences based on random effects model using the method of DerSimonian and Laird. ${ }^{28}$ If data availability allowed, we planned to perform subgroup analyses for the PRO outcome between participants who did, or not, achieve traction release at day 28 .

\section{Results}

\section{Description of studies}

Results of the search

In total 88 records were identified (Figure 1) of which 86 emerged from the three database searches. The electronic search was complemented by manually searching the reference lists of relevant articles in the databases and contacting the manufacturer for unpublished data related to PRO measures. This resulted in one additional publication and one conference presentation.

After excluding 20 duplicate records, 68 records were screened based on title and abstract. From these, 31 references failed to meet the eligibility criteria: detailed anatomical, visual acuity, safety outcomes (8) or clinical reviews (3) rather than PRO; expert opinion (6); case reports (5); predictive studies (2); other intervention (2); measurement technique to characterize macular structure and visual function (1); association anatomical and VA outcomes (1); study cost analysis (1); clinical trial number (1); abstract unavailable

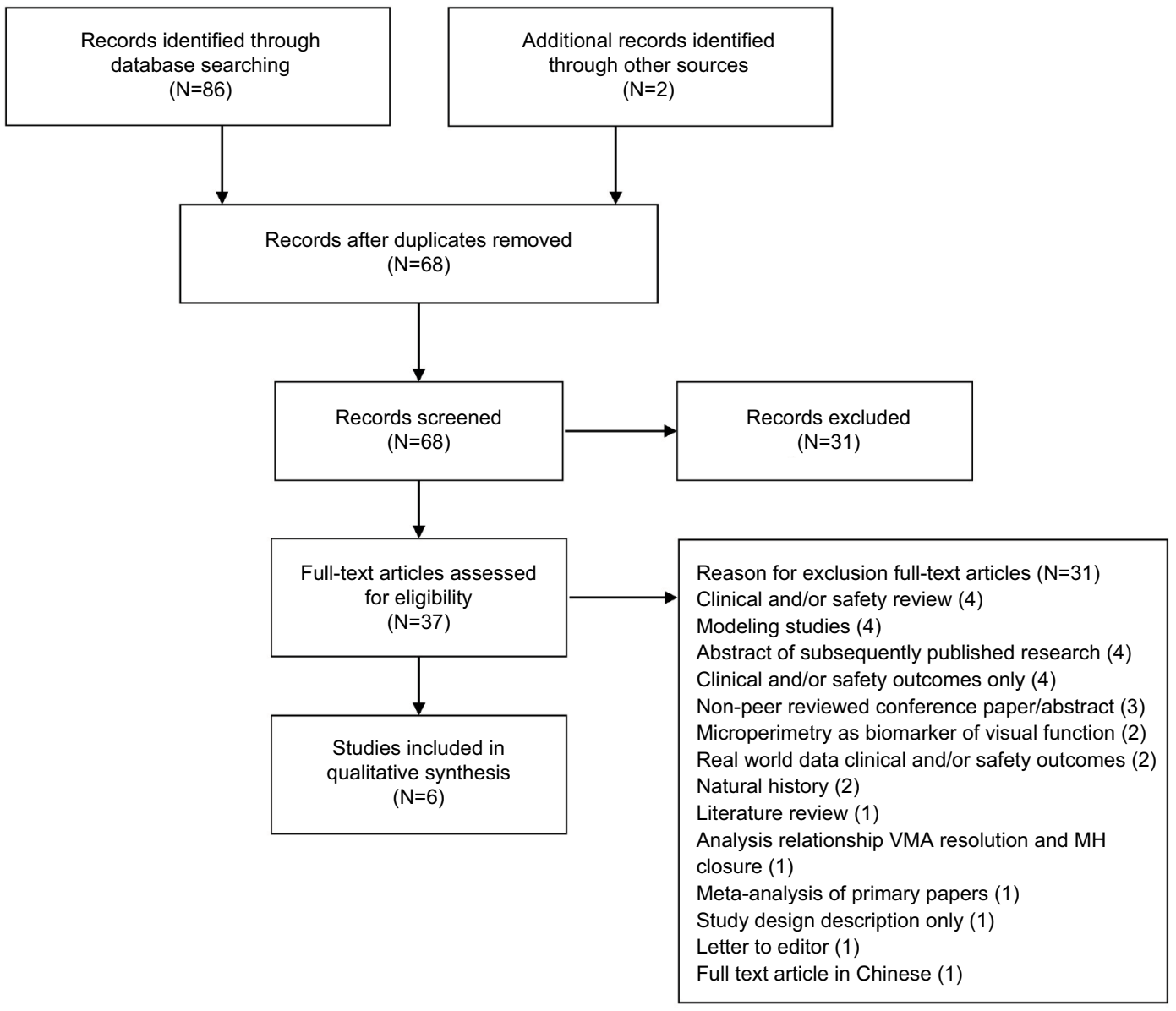

Figure I Study flow diagram

Abbreviations: VMA, vitreomacular adhesion; $\mathrm{MH}$, macular hole. 
(1). For the remaining 37 possibly relevant records, full-text publications were investigated, of which 31 articles were eliminated from the review for the following reasons: clinical and/or safety review (4); modeling study (4); abstracts of original research already included in the review (4); clinical and/or safety outcomes (4); non-peer reviewed conference paper or abstract only (3); microperimetry studies (2); real world data on clinical and/or safety outcomes (2); natural history on spontaneous resolution or visual acuity outcomes (2); analysis on interrelations between anatomical outcomes and/or visual acuity (1); literature review of symptomatic VMA (1); meta-analysis of primary papers (1); letter to editor (1); study design description (1); full-text in Chinese (1). Figure 1 presents the study flow diagram with numbers of records screened, assessed for eligibility and included in the review. A total of six publications were included in this review: two reports of three RCTs: Stalmans et al, ${ }^{11}$ Dugel et $\mathrm{al},{ }^{12}$ and four reports that analyzed PRO outcomes from the same RCT: Gandorfer et al, ${ }^{23}$ Varma et al, ${ }^{29}$ Jackson et al, ${ }^{26}$ Lescrauwaet et al. ${ }^{30}$

\section{Included studies}

Six publications met the eligibility criteria. A brief summary of the study characteristics is provided below, and further details are provided in Table 1.

\section{Participants}

The three RCTs included 872 participants (872 eyes): Microplasmin for Intravitreous Injection - Traction Release without Surgical Treatment (MIVI-TRUST) 006, N=326; MIVI-TRUST 007, N=326 (clinicaltrials.gov identifier: NCT00781859 and NCT00798317, respectively); Ocriplasmin for Treatment for Symptomatic Vitreomacular Adhesion Including Macular Hole (OASIS) trial, $\mathrm{N}=220$ (clinicaltrials. gov identifier: NCT01429441). The age range was 18-97 years (Table 2). In the OASIS study, eyes with an epiretinal membrane (ERM) were excluded but otherwise the eligibility criteria were similar across studies.

\section{Interventions}

MIVI-TRUST 006 and MIVI-TRUST 007 both compared a single injection of ocriplasmin $0.125 \mathrm{mg}$ with a placebo (saline) injection, while the OASIS study compared ocriplasmin $0.125 \mathrm{mg}$ with a sham injection (syringe hub pressed into conjunctiva to simulate an injection) which was assumed to better reflect natural history by removing a possible mechanical or volume effect of the saline injection causing VMA resolution. ${ }^{12}$

\section{Outcomes}

In the two primary research papers by Stalmans et $\mathrm{al}^{11}$ and Dugel et $\mathrm{al}^{12}$ the emphasis of the reported data involved clinical efficacy outcomes such as the primary endpoint of pharmacologic VMA resolution at day 28, secondary endpoints including BCVA gain from baseline, nonsurgical macular hole closure, need for vitrectomy and safety outcomes with ocriplasmin as observed in the RCTs. Both primary study reports summarize results for the VFQ-25 composite score, however, at different time points (month 6 in MIVI-TRUST; month 24 in OASIS). The report by Gandorfer et al focused on investigating the association between anatomical and functional outcomes, more specifically to describe how VMA resolution and macular hole closure in the MIVI-TRUST clinical trials impact visual function improvement (BCVA or VFQ-25). ${ }^{23}$

The report by Varma et al comprehensively described PRO data with ocriplasmin using the VFQ-25, more specifically change from baseline to month 6 for the composite and subscale scores and clinically meaningful change ( $\geq 5$ points) in scores. ${ }^{29}$ In these four papers, the functional outcomes considered were unidimensional (either visual acuity or VFQ-25). In addition, all results were reported irrespective of vitrectomy, meaning if a patient's eye disease deteriorated and required a vitrectomy this was not considered as a treatment failure (or nonresponse). The two reports by Jackson et $\mathrm{al}^{26}$ and Lescrauwaet et al $^{30}$ also reported secondary outcomes from the same RCTs, however, a patient-centered composite endpoint consisting of visual acuity, VFQ-25 and need for vitrectomy was reported. In these responder analyses, a patient was considered a visual function responder when a clinically meaningful improvement in any of these principal traits of visual functioning was achieved, without the need for a vitrectomy.

\section{Data synthesis}

The search identified six papers with comparative PRO data on ocriplasmin vs placebo or sham injection from three trials. No trial reported data for the same PRO measure. Due to differences in PRO methodology, a random-effect model was used to synthesize the individual study results.

\section{Excluded studies}

We excluded 31 papers after reviewing full-text copies (Table $\underline{\mathrm{S} 2}$ for details.

\section{Risk of bias in included studies}

The authors' judgements about each risk of bias item (random sequence generation; allocation concealment; blinding 
Table I Characteristics of studies included in the review (partially extracted from Neffendorf et al $^{16}$ )

\begin{tabular}{|c|c|}
\hline PICOS & Study characteristics \\
\hline \multicolumn{2}{|c|}{ Enzymatic vitreolysis with ocriplasmin for vitreomacular traction and macular holes Stalmans et al" } \\
\hline Participants & $\begin{array}{l}\text { Inclusion criteria: aged }>18 \text { years; focal VMA (vitreous adhesion to macula within } 6 \mathrm{~mm} \text { central retinal field surrounded } \\
\text { by elevation of posterior vitreous cortex, as seen on OCT) that in the opinion of investigator was related to decreased } \\
\text { visual function (eg, metamorphopsia, decreased visual acuity or other visual complaint); BCVA } \leq 20 / 25 \text { in study eye; BCVA } \\
\geq 20 / 800 \text { in non-study eye. } \\
\text { Exclusion criteria: any evidence of proliferative retinopathy or exudative AMD or retinal vein occlusion in study eye; } \\
\text { people with any vitreous hemorrhage or any other vitreous opacification which precludes either: visualization of posterior } \\
\text { pole by visual inspection OR adequate assessment of macula by either OCT or fluorescein angiogram (or both) in study } \\
\text { eye; FTMH }>400 \mu \mathrm{m} \text { in diameter in study eye; aphakia in study eye; high myopia ( }>-8 \text { diopters); uncontrolled glaucoma; } \\
\text { lenticular or zonular instability; history of retinal detachment in either eye; prior vitrectomy or prior laser photocoagulation } \\
\text { of macula; treatment with ocular surgery, intravitreal injection or retinal laser photocoagulation in the previous } 3 \text { months. }\end{array}$ \\
\hline $\begin{array}{l}\text { Intervention and } \\
\text { Comparator }\end{array}$ & $\begin{array}{l}\text { Single intravitreal injection of ocriplasmin } 125 \mu \mathrm{g} \text { in } 0.10 \mathrm{~mL} \text { volume. } \\
\text { Single intravitreal injection of } 0.10 \mathrm{~mL} \text { placebo with identical drug vehicle diluted with saline. }\end{array}$ \\
\hline $\begin{array}{l}\text { Outcomes, } \\
\text { including the } \\
\text { PRO measure }\end{array}$ & $\begin{array}{l}\text { Primary outcome, as defined in study reports: the primary endpoint was the proportion of eyes with nonsurgical } \\
\text { resolution of VMA at day } 28 \text { post-injection, as determined by masked OCT evaluation obtained from the CRC } \\
\text { Secondary outcomes, as defined in study reports: proportion of eyes with total PVD at day } 28 \text {, as determined by B-scan } \\
\text { ultrasound; need for vitrectomy; closure of a FTMH; gain } \geq 3 \text {-lines BCVA without vitrectomy; change from baseline in } \\
\text { BCVA and VFQ- } 25 \text { score at } 6 \text { months. } \\
\text { Adverse events reported: yes } \\
\text { Intervals at which outcomes assessed: } 7,14,28,90 \text { and I } 80 \text { days }\end{array}$ \\
\hline Study design & $\begin{array}{l}\text { Randomized controlled trials: MIVI } 6 \text { and MIVI 7, with pooled analysis } \\
\text { Length of follow-up: } 180 \text { days } \\
\text { Years study conducted: } 2008-2010\end{array}$ \\
\hline \multicolumn{2}{|c|}{ Results of the 2-year ocriplasmin for treatment for symptomatic vitreomacular adhesion including macular hole (oasis) randomized trial Dugel et al' } \\
\hline Participants & $\begin{array}{l}\text { Inclusion criteria: aged }>18 \text { years; presence of symptomatic VMA/VMT; BCVA } \leq 20 / 32 \text { in study eye; BCVA } \geq 20 / 800 \text { in } \\
\text { non-study eye } \\
\text { Exclusion criteria: history or current evidence of PR, exudative AMD or retinal vein occlusion in the study eye; } \\
\text { people with any vitreous hemorrhage or any other vitreous opacification which precludes either visualization of the } \\
\text { posterior pole by visual inspection OR adequate assessment of the macula by OCT; MH }>400 \mu m \text { in diameter in the } \\
\text { study eye; presence of epiretinal membrane; aphakia in study eye; high myopia ( }>-8 \text { diopters in study eye); history of } \\
\text { rhegmatogenous retinal detachment in either eye; prior vitrectomy in study eye; previous participation in this trial or } \\
\text { prior administration of ocriplasmin in study eye. }\end{array}$ \\
\hline $\begin{array}{l}\text { Intervention and } \\
\text { Comparator }\end{array}$ & $\begin{array}{l}\text { Single intravitreal injection of ocriplasmin } 125 \mu \mathrm{g} \text { in } 0.10 \mathrm{~mL} \text { volume. } \\
\text { Sham (the same syringe hub was pressed against the conjunctiva to simulate an injection). }\end{array}$ \\
\hline $\begin{array}{l}\text { Outcomes, } \\
\text { including the } \\
\text { PRO measure }\end{array}$ & $\begin{array}{l}\text { Primary outcome, as defined in study reports: Proportion of subjects with pharmacological VMA/VMT resolution at day } \\
\text { 28. Pharmacological VMA resolution without anatomical defect, based on spectral domain optical coherence tomography } \\
\text { and determined by the masked CRC, with post-resolution vitrectomy considered as a failure. } \\
\text { Secondary outcomes, as defined in study reports, were assessed at } 24 \text { months and irrespective of vitrectomy (where } \\
\text { applicable): proportion of subjects with a } \geq 2 \text {-lines improvement in BCVA from baseline at month 24; proportion of } \\
\text { FTMHs that closed without vitrectomy as determined by the CRC; proportion of subjects receiving a vitrectomy; } \\
\text { proportion of subjects with a } \geq 3 \text {-line improvement in BCVA from baseline; mean change in BCVA from baseline; and } \\
\text { proportion of subjects with a } \geq 5 \text {-point improvement in the VFQ-25 composite score from baseline. } \\
\text { Adverse events reported: yes } \\
\text { Intervals at which outcomes assessed: } 7 \text { and } 28 \text { days; } 3,6,9,12,15,18,21 \text { and } 24 \text { months }\end{array}$ \\
\hline Study design & $\begin{array}{l}\text { Randomized controlled trial } \\
\text { Length of follow-up; } 24 \text { months } \\
\text { Years of study conducted: } 201 \mathrm{I}-2014\end{array}$ \\
\hline \multicolumn{2}{|c|}{$\begin{array}{l}\text { Association between anatomical resolution and functional outcomes in the mivi-trust studies using ocriplasmin to treat symptomatic vitreomacular } \\
\text { adhesion/vitreomacular traction, including when associated with macular hole Gandorfer et al }{ }^{23}\end{array}$} \\
\hline Participants & Pooled MIVI 6 and MIVI 7 study population as reported by Stalmans et al." \\
\hline $\begin{array}{l}\text { Intervention and } \\
\text { Comparator }\end{array}$ & $\begin{array}{l}\text { Single intravitreal injection of ocriplasmin } 125 \mu \mathrm{g} \text { in } 0.10 \mathrm{~mL} \text { volume. } \\
\text { Single intravitreal injection of } 0.10 \mathrm{~mL} \text { placebo with identical drug vehicle diluted with saline. }\end{array}$ \\
\hline $\begin{array}{l}\text { Outcomes, } \\
\text { including the } \\
\text { PRO measure }\end{array}$ & $\begin{array}{l}\text { BCVA: mean and categorical changes from baseline in BCVA (irrespective of vitrectomy). } \\
\text { VFQ-25: mean changes from baseline in the VFQ- } 25 \text { scores. } \\
\text { Responder analyses by success or failure to achieve nonsurgical resolution of VMA at day } 28 \text { and nonsurgical FTMH } \\
\text { closure at day } 28 \text {. }\end{array}$ \\
\hline
\end{tabular}


Table I (Continued)

\begin{tabular}{|c|c|}
\hline PICOS & Study characteristics \\
\hline $\begin{array}{l}\text { Study design } \\
\text { and notes }\end{array}$ & $\begin{array}{l}\text { Analyses from randomized controlled studies MIVI } 6 \text { and MIVI } 7 \\
\text { An ANOVA model with factors for subgroup (success/failure on the anatomical endpoint), study, and baseline visual } \\
\text { acuity category ( }<65,65-75,>75 \text { letters) was used to compare between responder subgroups. A similar model was used } \\
\text { for VFQ- } 25 \text { with a factor adjusting for baseline in the VFQ- } 25 \text {. } \\
\text { For categorical changes in BCVA, the Cochran-Mantel- Haenszel test, stratified by study, was used to make comparisons } \\
\text { between responder subgroups. }\end{array}$ \\
\hline \multicolumn{2}{|c|}{$\begin{array}{l}\text { Improvement in patient-reported visual function after ocriplasmin for vitreomacular adhesion results of the microplasmin for intravitreous } \\
\text { injection-traction release without surgical treatment (mivi-trust) trials Varma et al }{ }^{29}\end{array}$} \\
\hline Participants & Pooled MIVI 6 and MIVI 7 study population as reported by Stalmans et al." \\
\hline $\begin{array}{l}\text { Intervention and } \\
\text { Comparator }\end{array}$ & $\begin{array}{l}\text { Single intravitreal injection of ocriplasmin } 125 \mu \mathrm{g} \text { in } 0.10 \mathrm{~mL} \text { volume. } \\
\text { Single intravitreal injection of } 0.10 \mathrm{~mL} \text { placebo with identical drug vehicle diluted with saline. }\end{array}$ \\
\hline $\begin{array}{l}\text { Outcomes, } \\
\text { including the } \\
\text { PRO measure }\end{array}$ & $\begin{array}{l}\text { VFQ- } 25 \text { composite and subscale scores } \\
\text { Mean changes between baseline and 6-month follow-up. } \\
\text { Proportion of patients with a clinically meaningful change ( } \geq 5 \text { points) in scores. }\end{array}$ \\
\hline $\begin{array}{l}\text { Study design } \\
\text { and notes }\end{array}$ & $\begin{array}{l}\text { Analyses from } 2 \text { randomized controlled clinical trials comparing change in patient-reported visual function. } \\
\text { Comparison ocriplasmin vs placebo: (I) mean changes from baseline in VFQ-25 scores*; (2) proportion of patients } \\
\text { with } \geq 5 \text {-point improvement or worsening in VFQ- } 25 \text { scores.** } \\
\text { Comparison ocriplasmin patients who met the primary endpoint vs those who did not: (I) mean changes from baseline in } \\
\text { VFQ- } 25 \text { scores; (2) proportions of patients with } \geq 5 \text {-point improvement or worsening in VFQ-25 scores.** }\end{array}$ \\
\hline \multicolumn{2}{|c|}{ Visual function response to ocriplasmin for the treatment of vitreomacular traction and macular hole Jackson et a ${ }^{26}$} \\
\hline Participants & Pooled MIVI 6 and MIVI 7 study population as reported by Stalmans et al." \\
\hline $\begin{array}{l}\text { Intervention and } \\
\text { Comparator }\end{array}$ & $\begin{array}{l}\text { Single intravitreal injection of ocriplasmin } 125 \mu \mathrm{g} \text { in } 0.10 \mathrm{~mL} \text { volume. } \\
\text { Single intravitreal injection of } 0.10 \mathrm{~mL} \text { placebo with identical drug vehicle diluted with saline. }\end{array}$ \\
\hline $\begin{array}{l}\text { Outcomes, } \\
\text { including the } \\
\text { PRO measure }\end{array}$ & $\begin{array}{l}\text { The main outcome measure was visual function response at } 6 \text { months, defined as either a BCVA improvement of } \geq 2 \\
\text { lines; or an improvement in the composite score of the VFQ- } 25 \text { exceeding the MCID, estimated using the standard error } \\
\text { of measurement approach; or an improvement in the VFQ- } 25 \text { driving subscale score exceeding the MCID. }\end{array}$ \\
\hline Study design & $\begin{array}{l}\text { Post hoc analysis of prespecified secondary endpoints in two multicenter, randomized, double-masked, Phase III clinical } \\
\text { trials }\end{array}$ \\
\hline \multicolumn{2}{|c|}{ Visual function response to ocriplasmin for the treatment of vitreomacular traction and macular hole: the oasis study Lescrauwaet et al ${ }^{30}$} \\
\hline Participants & OASIS study population as reported by Dugel et al. ${ }^{12}$ \\
\hline $\begin{array}{l}\text { Intervention and } \\
\text { Comparator }\end{array}$ & $\begin{array}{l}\text { Single intravitreal injection of ocriplasmin } 125 \mu \mathrm{g} \text {. } \\
\text { Sham }\end{array}$ \\
\hline $\begin{array}{l}\text { Outcomes, } \\
\text { including the } \\
\text { PRO measure }\end{array}$ & $\begin{array}{l}\text { The main outcome measure was the visual function response at month } 6 \text {, with further assessments at months } 12 \text { and } 24 \text {. } \\
\text { VFR was defined as either a VA improvement of } \geq 2 \text { lines or an improvement exceeding the MCID in the composite or the } \\
\text { mental health subscale scores of the VFQ-25. The MCID was estimated using the standard error of measurement approach. }\end{array}$ \\
\hline Study design & Prespecified analysis of secondary endpoints from a randomized controlled trial (OASIS study). \\
\hline
\end{tabular}

Notes: *ANOvA model, with treatment, age, sex, race, baseline vFQ-25 score, and study as covariates. **Cochran-Mantel-Haenszel test, with stratification for age group, sex, race, and study. Reprinted with permission from Neffendorf JE, Kirthi V, Pringle E, Jackson TL. Ocriplasmin for symptomatic vitreomacular adhesion. Cochrane Database Syst Rev. 2017;10:CD01 1874, John Wiley and Sons. ${ }^{16}$

Abbreviations: BCVA, best corrected visual acuity; $\mathrm{CRC}$, central reading center; FTMH, full-thickness macular hole; $\mathrm{MH}$, macular hole; $\mathrm{MCID}$, minimal clinically important difference; OCT, optical coherence tomography; PR, proliferative retinopathy; PVD, posterior vitreous detachment; PICOS, Participants Interventions Comparators Outcomes Study design;VFQ-25, Visual Function Questionnaire 25;VFR, visual function response; VMA, vitreomacular adhesion; VMT, vitreomacular traction; AMD, age-related macular degeneration.

of participants and personnel; incomplete outcome data; selective reporting; other bias) for each RCT is summarized in Figure S1. Overall, the studies were judged to have a low risk of bias based on the diagram provided.

\section{Results of individual studies}

Demographic and ocular baseline characteristics were generally comparable between treatment groups. As reported previously, $22.8 \%$ vs $25.0 \%$ of MIVI-TRUST patients had a FTMH associated with VMT at baseline in the ocriplasmin vs placebo group, respectively. ${ }^{11,29}$ In OASIS, these proportions were slightly higher, but remained comparable between ocri- plasmin (34.5\%) vs sham (35.6\%) groups. ${ }^{12}$ Mean baseline BCVA scores (ETDRS letters) were similar across studies and treatments: 63.9 vs 65.1 letters in the MIVI-TRUST ocriplasmin vs placebo groups, respectively, ${ }^{11,29}$ and 63.5 vs 62.4 letters in the ocriplasmin vs sham OASIS groups, respectively. ${ }^{12}$ Mean baseline composite VFQ-25 scores were lower for ocriplasmin: 77.1 vs 82.0 in the MIVI-TRUST ocriplasmin vs placebo groups, respectively ${ }^{29}$ and 77.6 vs 81.8 in the OASIS ocriplasmin vs sham groups (Mein, 2017, conference proceeding, unpublished data). Mean general vision subscale scores were 62.1 (ocriplasmin) and 65.5 (placebo). ${ }^{29}$ Table 2 shows baseline characteristics across 
Table 2 Baseline characteristics of patients with VMT in investigational studies

\begin{tabular}{|c|c|c|c|c|}
\hline & $\begin{array}{l}\text { MIVI } 006 \\
(\mathrm{~N}=326)\end{array}$ & $\begin{array}{l}\text { MIVI } 007 \\
(N=326)\end{array}$ & $\begin{array}{l}\text { OASIS }^{a} \\
(\mathrm{~N}=2 \mid 8)\end{array}$ & $\begin{array}{l}\text { Combined } \\
(\mathrm{N}=\mathbf{8 7 0})\end{array}$ \\
\hline \multicolumn{5}{|l|}{ Demographics } \\
\hline Female N (\%) & $207(63.5)$ & $222(68.1)$ & 147 (67.4) & $576(66.2)$ \\
\hline White race $\mathrm{N}(\%)$ & $292(89.6)$ & $310(95.1)$ & $195(89.4)$ & $797(91.6)$ \\
\hline Age, years: mean (SD) & $71.3(10.2)$ & $72.0(8.5)$ & $69.1(10.3)$ & 7I (9.7) \\
\hline \multicolumn{5}{|l|}{ Anatomical characteristics } \\
\hline FTMH present $\mathrm{N}(\%)$ & $89(27.3)$ & $64(19.6)$ & $76(34.9)$ & $229(26.3)$ \\
\hline ERM present $\mathrm{N}(\%)$ & $121(37.7)$ & $|3|(40.9)$ & $50(22.9)$ & $302(35.2)$ \\
\hline \multicolumn{5}{|l|}{ Ocular characteristics } \\
\hline BCVA, mean (SD) ${ }^{\mathrm{b}}$ & $64.8(10.5)$ & $63.8(13.2)$ & $63.0(9.8)$ & $64.0(11.5)$ \\
\hline \multicolumn{5}{|l|}{ VFQ-25 composite score ${ }^{c, d}$} \\
\hline VFQ-CS, mean (SD) & $80.2(14.1)$ & $76.8(15.8)$ & $78.9(14.4)$ & $78.6(14.9)$ \\
\hline
\end{tabular}

Notes: ${ }^{a} \mathrm{~A}$ total of 220 participants received trial treatment, however one subject in each treatment group did not attend a post-injection visit and both were therefore not included in the full analysis population. 'Baseline BCVA measurements were not available for I MIVI 006 and I OASIS participant. 'Composite score is calculated as the mean of the II vision-targeted subscale scores, excluding the general health question. ${ }^{25}$ Baseline VFQ-CS data were not available for I MIVI 006 and 2 MIVI 007 participants. Abbreviations: ERM, epiretinal membrane; FTMH, full-thickness macular hole; VFQ-25, visual function questionnaire, 25-item form²4; BCVA, best-corrected visual acuity; VMT, Vitreomacular traction; MIVI, Microplasmin for Intravitreous Injection; OASIS, Ocriplasmin for Treatment for Symptomatic Vitreomacular Adhesion Including Macular Hole.

the individual ocriplasmin studies (MIVI 006, MIVI 007, OASIS), and the combined studies.

Notwithstanding differences in anatomical disease characteristics across the individual studies, baseline BCVA was quite comparable across studies, while functional vision (measured by the VFQ-25) showed more variability (Table 2).

\section{Burden of visual dysfunction in VMT}

Evaluating visual dysfunction brings important information to determine the need for treatment. The MIVI-TRUST and OASIS trials collected PRO outcomes (VFQ-25 data) prior to treatment with ocriplasmin or control, and give an insight into the impact of VMT. The baseline VFQ-25 subscale scores are summarized in Table 3. Table 3 also shows the scores for several chronic eye diseases, low vision and the healthy reference groups examined in the NEI VFQ Field Test, for comparison..$^{24}$ Most VMT subscale scores were lower than the healthy reference group, and with greater variability (represented by the SD), suggesting the impact of VMT varies substantially between individuals.

In the ocriplasmin studies, patients reported their visual disability at baseline as being the greatest for the general vision subscale, with a mean score of approximately $63 .{ }^{29} \mathrm{The}$ next three most impacted vision-targeted domains in VMT patients were near activities (score $=69$ ), mental health (score $=71$ ) and role functioning (score $=72$ ) (Figure 2).

\section{Effect of treatment on patient reported outcomes}

Compared with no treatment, ocriplasmin was found to increase the chance of traction resolution within 28 days. ${ }^{16}$ What the treatment effect on a surrogate (anatomical) endpoint signifies in terms of improved patient functioning is synthesized for two PROs, namely the VFQ-25 composite score and the visual function response measures.

\section{Visual Function Questionnaire-25 items}

In MIVI-TRUST, short-term (month 6), improvements from baseline in the VFQ-25 composite score and each subscale score were numerically better in the ocriplasmin vs the placebo group, with a notable improvement in the general vision subscale score in favor of ocriplasmin (6.1, ocriplasmin vs 2.1, placebo). Improvements in the composite score were 3.4 (ocriplasmin) vs 0.7 (placebo). ${ }^{11,23,29}$

Assuming a $\geq 5$-point improvement as clinically meaningful, a greater proportion of ocriplasmin-treated patients (36.0\%) had meaningful increase in the NEI VFQ-25 composite score vs placebo $(27.2 \%) .{ }^{29}$ In OASIS, this treatment difference $(21.3 \%)$ was maintained in the long-term (month $24)$ in favor of ocriplasmin $(51.4 \%)$ vs sham $(30.1 \%){ }^{12}$ Results were reported regardless of whether the patient underwent a vitrectomy or not, and the analysis applied last observation carried forward for missing values.

Combining the total of 870 participants from the individual studies, the pooled results for the VFQ-25 composite score responder analysis shows a higher proportion of patients (11.8\%) experience a clinically meaningful improvement in visual functioning with ocriplasmin compared to control (Table 4).

\section{Visual function response - a composite endpoint}

From the ocriplasmin clinical studies, a composite functional endpoint called visual function response (VFR) was developed. ${ }^{26}$ This endpoint was composed of three scores (clinical 
Table 3 VFQ-25 subscale scores in selected vision conditions from the NEI VFQ field test sample ( $n=597)$ and in VMT studies

\begin{tabular}{|c|c|c|c|c|c|c|c|c|}
\hline & $\begin{array}{l}\text { Diabetic } \\
\text { retinopathy }\end{array}$ & AMD & Glaucoma & Cataract & $\begin{array}{l}\text { CMV } \\
\text { retinitis }\end{array}$ & Low vision & $\begin{array}{l}\text { Healthy } \\
\text { reference } \\
\text { group }\end{array}$ & $\begin{array}{l}\text { VMT } \\
\text { - MIVI, } \\
\text { OASIS }\end{array}$ \\
\hline & $(N=123)$ & $(N=108)$ & $(\mathrm{N}=77)$ & $(\mathrm{N}=93)$ & $(\mathrm{N}=37)$ & $(\mathrm{N}=90)$ & $(N=122)$ & $(\mathrm{N}=870)$ \\
\hline \multicolumn{9}{|c|}{ Subscales (mean \pm SD) } \\
\hline General health & $46 \pm 25$ & $65 \pm 25^{\mathrm{a}, \mathrm{b}}$ & $62 \pm 25^{\mathrm{a}, \mathrm{b}}$ & $55 \pm 25$ & $45 \pm 24$ & $57 \pm 27$ & $69 \pm 24$ & $61 \pm 24$ \\
\hline General vision & $62 \pm 21$ & $53 \pm 20$ & $71 \pm 17$ & $60 \pm 17$ & $76 \pm 14^{b}$ & $38 \pm 18$ & $83 \pm 15$ & $63 \pm 16$ \\
\hline Near vision & $63 \pm 30$ & $54 \pm 27$ & $79 \pm 23$ & $73 \pm 21$ & $84 \pm 20^{b}$ & $36 \pm 23$ & $92 \pm 13$ & $69 \pm 21$ \\
\hline Distance vision & $66 \pm 30$ & $56 \pm 29$ & $77 \pm 25$ & $73 \pm 22$ & $84 \pm 18$ & $38 \pm 26$ & $93 \pm 11$ & $75 \pm 20$ \\
\hline Driving & $55 \pm 40$ & $39 \pm 36$ & $75 \pm 28$ & $63 \pm 30$ & $80 \pm 28^{a, b}$ & $10 \pm 23$ & $87 \pm 18$ & $76 \pm 24$ \\
\hline Peripheral vision & $78 \pm 29$ & $77 \pm 27$ & $76 \pm 27$ & $87 \pm 21$ & $78 \pm 21$ & $59 \pm 32$ & $97 \pm 10$ & $83 \pm 22$ \\
\hline Color vision & $90 \pm 22$ & $85 \pm 25$ & $93 \pm 17$ & $90 \pm 20$ & $98 \pm 9^{a, b}$ & $7 I \pm 3 I$ & $98 \pm 8$ & $94 \pm 14$ \\
\hline Ocular pain & $88 \pm 17^{a, b}$ & $87 \pm 16^{\mathrm{a}}$ & $89 \pm 14^{\mathrm{a}, \mathrm{b}}$ & $86 \pm 19^{b}$ & $90 \pm 16^{\mathrm{a}, \mathrm{b}}$ & $85 \pm 20^{a, b}$ & $90 \pm 15$ & $84 \pm 19$ \\
\hline \multicolumn{9}{|c|}{ Vision specific (mean \pm SD) } \\
\hline Role difficulties & $69 \pm 31$ & $6 I \pm 31$ & $84 \pm 23$ & $76 \pm 22$ & $78 \pm 24$ & $44 \pm 29$ & $93 \pm 13$ & $72 \pm 26$ \\
\hline Dependency & $77 \pm 30$ & $72 \pm 30$ & $92 \pm 19$ & $88 \pm 20$ & $89 \pm 12$ & $5 I \pm 3 I$ & $99 \pm 5$ & $88 \pm 20$ \\
\hline Social functioning & $8 I \pm 26$ & $73 \pm 29$ & $89 \pm 20$ & $87 \pm 19$ & $96 \pm 9$ & $50 \pm 31$ & $99 \pm 3$ & $91 \pm 16$ \\
\hline Mental health & $66 \pm 29$ & $58 \pm 27$ & $8 I \pm 20$ & $77 \pm 22$ & $74 \pm 22$ & $46 \pm 27$ & $92 \pm 12$ & $7 I \pm 23$ \\
\hline Composite score & $72 \pm 22$ & $65 \pm 21$ & $82 \pm 17$ & $78 \pm 14$ & $84 \pm 11$ & $49 \pm 19$ & $93 \pm 7$ & $79 \pm 15$ \\
\hline
\end{tabular}

Notes: Composite score data provided by Mangione and colleagues. a Unadjusted $t$-test comparison with healthy reference group participants was nonsignificant $(P<0.05)$. 'Linear regression result for 2 -group comparison with the health reference group, adjusted for age, sex, race, and medical comorbidities, was nonsignificant ( $P<0.05)$. 'Data are presented as mean \pm SD. All pairwise comparisons between each disease group and the healthy reference group were statistically significant at $P<0.05$, unless otherwise specified.

Abbreviations: CMV, cytomegalovirus; AMD, age-related macular degeneration; VFQ-25, Visual Function Questionnaire 25; VMT, vitreomacular traction; MIVI, Microplasmin for Intravitreous Injection; OASIS, Ocriplasmin for Treatment for Symptomatic Vitreomacular Adhesion Including Macular Hole.

Table 4 Responder analysis for VFQ-25 composite score across studies (month 6 data) - irrespective of vitrectomy

\begin{tabular}{|c|c|c|c|c|}
\hline Response criteria: composite score ${ }^{a}$ & Ocriplasmin \% (n/N) & Control \% (n/N) & Difference (\%) $(95 \% \mathrm{Cl})^{\mathrm{b}}$ & $P$-value \\
\hline Change from baseline $\geq 5$ points & & & & \\
\hline MIVI-TRUST & $36.0(154 / 428)$ & $27.2(47 / 173)$ & $8.8(0.8,16.9)$ & 0.045 \\
\hline OASIS $^{d}$ & $39.3(57 / 145)$ & $21.9(16 / 73)$ & $17.4(5.0,29.8)$ & 0.010 \\
\hline Combined & 36.8 & 25.4 & $11.8(3.8,19.7)$ & 0.004 \\
\hline
\end{tabular}

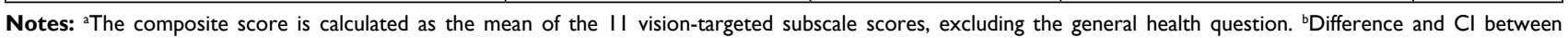
treatment groups are based on the percentage of responses. 'For individual studies, the $P$-value is from Fisher's exact test, comparing control and ocriplasmin. For combined studies, pooling of risk differences was based on random effects model using the method of DerSimonian and Laird. ${ }^{28}$ dEstimate based on non-stratified treatment effect, not weighted by FTMH strata.

Abbreviations: $\mathrm{N}$, number of subjects in the dataset; $\mathrm{n}$, number of subjects with a success for the endpoint; FTMH, full thickness macular hole; MIVI-TRUST, Microplasmin for Intravitreous Injection -Traction Release without Surgical Treatment; VFQ-25, Visual Function Questionnaire 25; OASIS, Ocriplasmin for Treatment for Symptomatic Vitreomacular Adhesion Including Macular Hole.

proxies) namely the VFQ-25 composite score (CS), VFQ-25 driving subscale and best corrected visual acuity (BCVA) in the case of the MIVI-TRUST analysis vs VFQ-CS, VFQmental health score (MHS) and BCVA in the case of the OASIS analysis. Overall VFR was defined as an improvement exceeding the threshold of minimally clinically important difference (MCID) in any of the three principal traits of visual functioning identified from the PCA. ${ }^{26,30}$ Figure 3 summarizes the VFR responder results from both analyses. Overall VFR was quite consistent; half or more of ocriplasmin-treated subjects were considered an "overall VFR responder" (MIVITRUST: $55.1 \%$; $51.0 \%$ in OASIS), while this was the case for only 1 in 3 of MIVI-TRUST placebo patients (34.2\%) and 1 in 4 of OASIS sham patients $(23.3 \%)$. In these responder analyses, a patient who required a vitrectomy surgery prior to the VFQ-25 assessment was automatically classified as a visual function nonresponder.

Combining the data from the individual studies, the pooled VFR results show $54.0 \%$ of ocriplasmin-treated patients experience a clinically meaningful improvement in visual functioning compared with $30.1 \%$ in the control group, representing a $23.2 \%$ difference (Table 5).

\section{Association between PROs and anatomical outcomes}

Release of vitreomacular traction was the primary endpoint in all RCTs of ocriplasmin which was measured as an imaging outcome by optical coherence tomography (OCT) ${ }^{11,12}$ These 


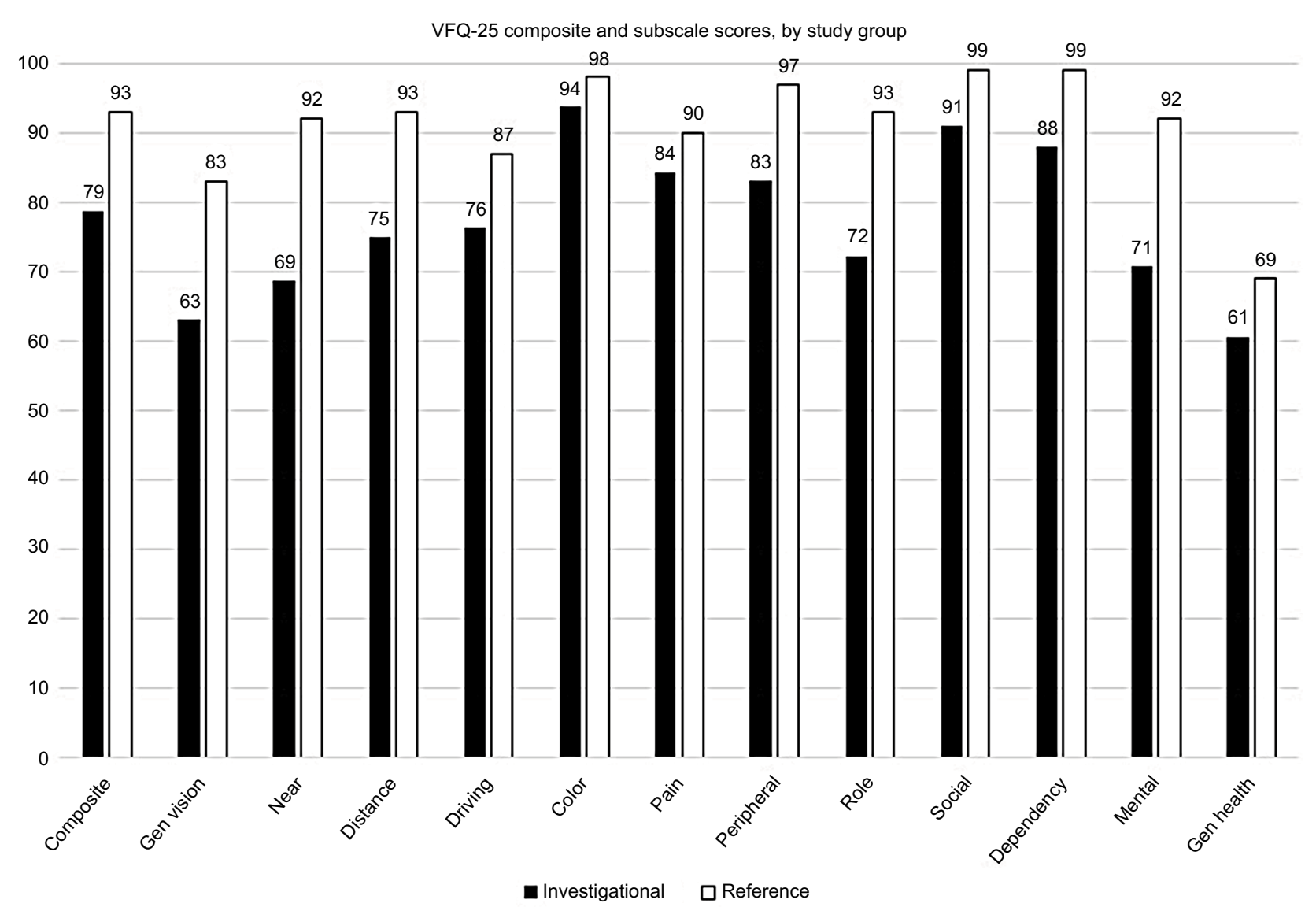

Figure 2 VFQ-25 composite and subscale scores for VMT patients (investigational and healthy reference groups).

Notes: All pairwise combinations between VMT patients from investigational studies (MIVI, OASIS) vs the healthy reference groups were statistically significant at $P<0.05$. Composite score for healthy reference group calculated as mean of II subscale scores, excluding general health item (courtesy of Mangione and colleagues).

Abbreviations: VFQ-25, Visual Function Questionnaire 25; VMT, vitreomacular traction; MIVI-TRUST, Microplasmin for Intravitreous Injection - Traction Release without Surgical Treatment; OASIS, Ocriplasmin for Treatment for Symptomatic Vitreomacular Adhesion Including Macular Hole.

surrogate (anatomical) outcomes are not of direct practical importance to patients, but are taken as being predictive of clinical outcomes (such as VA and QoL) of most importance to patients. ${ }^{31}$

Nonsurgical resolution of traction at day 28 was associated with functional outcomes: a 5-point improvement from baseline to month 6 was observed in the VFQ-25 composite score in patients (both treatment groups combined) who experienced a release of traction vs a 2-point improvement in those with persisting traction $(P=0.003){ }^{23}$

Within treatment groups, ocriplasmin-treated patients with successful release also had a significantly higher improvement on the composite score compared to those with persisting traction ( 7.7 vs $2.6, P=0.003$ ). However, this association was not observed in the placebo-treated patients $(-0.2$ vs $0.7, P=0.66){ }^{29}$

Significant associations were also found between a clinically meaningful functional response for the VFQ-CS, BCVA and overall VFR measures in patients who achieved release vs those with persisting adhesion (Figure 4) ${ }^{26,30}$

When pooling these results across the individual studies, we observed a higher proportion of patients with visual function response $(60.6 \%)$ when release of traction occurred at day 28 compared with $42.3 \%$ of patients with persisting traction (Table 6).

\section{Partial resolution of traction and treatment effect on PROs}

In all RCTs of ocriplasmin, successful VMA resolution was strictly defined as a progression from a state where the vitreous was attached in or at the macula to a state in which VMA at the macula was absent. In the subgroup of patients with release of traction, no significant differences in response were observed between ocriplasmin and control for the composite outcome VFR or the VFQ-25 composite score. In the subgroup with persisting adhesion/traction, a 
A

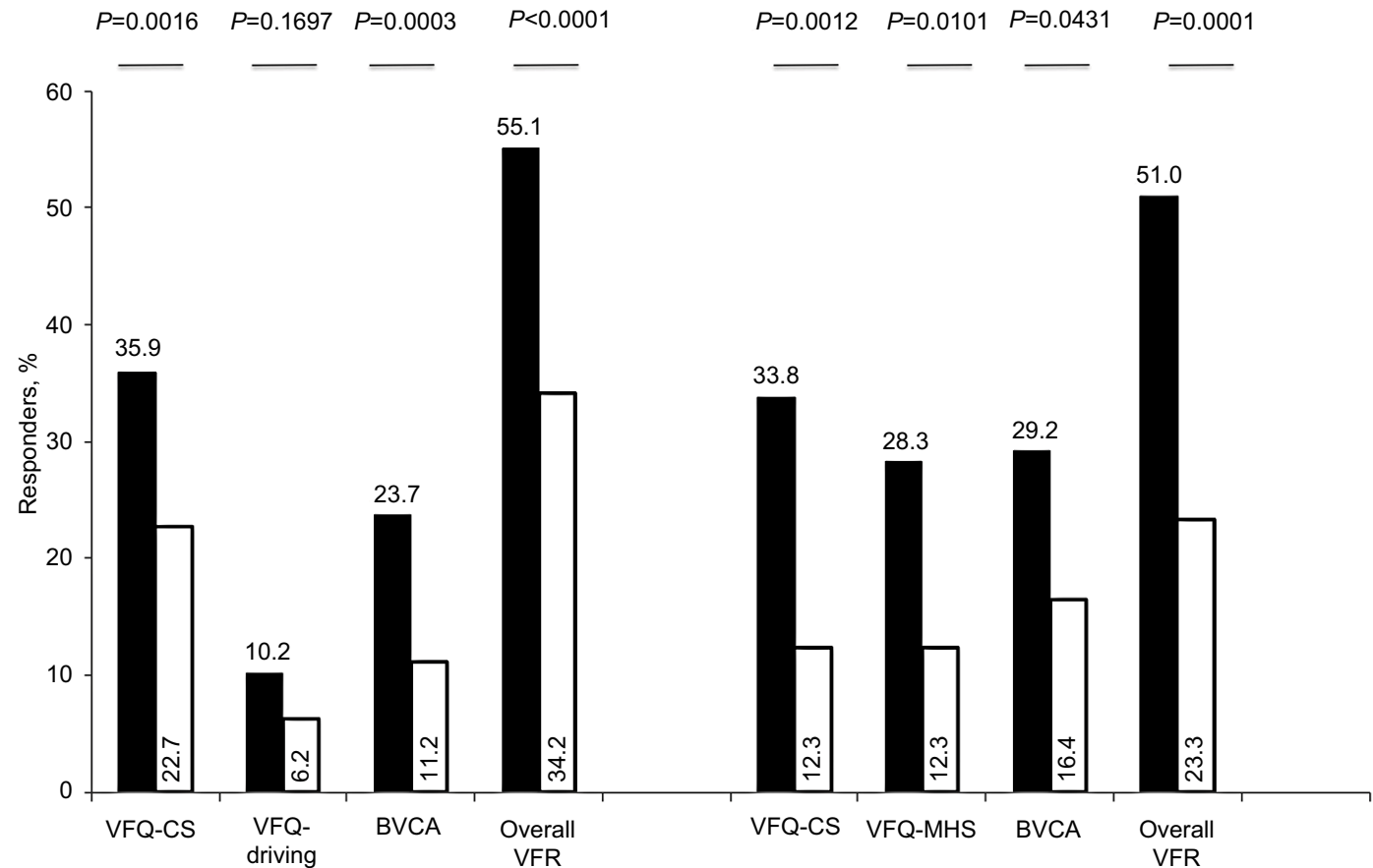

Figure 3 Responder rates for visual function response variables by treatment (month 6). (A) MIVI. (B) OASIS.

Abbreviations: BCVA, best corrected visual acuity; VFR, visual function response; VFQ-CS, Visual Function Questionnaire 25-composite score; VFQ-Driving, Visual Function Questionnaire 25-driving; VFQ-MHS, Visual Function Questionnaire 25-mental health subscale; MIVI-TRUST, Microplasmin for Intravitreous Injection - Traction Release without Surgical Treatment; OASIS, Ocriplasmin for Treatment for Symptomatic Vitreomacular Adhesion Including Macular Hole.

Table 5 Responder analysis for VFR across studies (month six data)

\begin{tabular}{|c|c|c|c|c|}
\hline Response criteria & $\begin{array}{l}\text { Ocriplasmin } \\
\%(\mathbf{n} / \mathbf{N})\end{array}$ & $\begin{array}{l}\text { Control } \\
\%(n / N)\end{array}$ & $\begin{array}{l}\text { Difference (\%) } \\
(95 \% \mathrm{Cl})^{\mathrm{b}}\end{array}$ & $P$-value ${ }^{c}$ \\
\hline Visual Function Response ${ }^{a}$ & & & & \\
\hline MIVI-TRUST & $55.1(217 / 394)$ & $34.2(53 / 155)$ & $20.9(11.9,29.8)$ & $<0.001$ \\
\hline $\mathrm{OASIS}^{d}$ & $51.0(74 / 145)$ & $23.3(17 / 73)$ & $27.7(15.1,40.4)$ & $<0.001$ \\
\hline Combined & 54.0 & 30.1 & $23.2(15.9,30.5)$ & $<0.001$ \\
\hline
\end{tabular}

Notes: ${ }^{a}$ Response criteria based on overall VFR composed of 3 dimensions determined by the PCA output (in MIVI-TRUST: VFQ-CS, VFQ-driving, BCVA; in OASIS VFQ$\mathrm{CS}, \mathrm{VFQ}-\mathrm{MH}, \mathrm{BCVA}$. 'Difference and $\mathrm{Cl}$ between treatment groups are based on the percentage of responses. 'For individual studies, the $P$-value is from Fisher's exact test, comparing control and ocriplasmin. For combined studies, pooling of risk differences was based on random effects model using the method of DerSimonian and Laird. ${ }^{28}$ ${ }^{d}$ Estimate based on non-stratified treatment effect, not weighted by FTMH strata.

Abbreviations: N, number of subjects in the dataset; $n$, number of subjects with a success for the endpoint; VFR, visual function response; PCA, principal component analysis; VFQ-CS, visual Function Questionnaire 25-composite score; VFQ-Driving, visual Function Questionnaire 25-driving subscale; VFQ-MHS, visual Function Questionnaire 25-mental health subscale; FTMH, full thickness macular hole; BCVA, best corrected visual acuity; MIVI-TRUST, Microplasmin for Intravitreous Injection - Traction Release without Surgical Treatment; OASIS, Ocriplasmin for Treatment for Symptomatic Vitreomacular Adhesion Including Macular Hole.

significantly higher proportion of functional responders was observed in the ocriplasmin-treated patients compared with the control group, for the overall VFR and VFQ-CS outcomes (Figure 5). ${ }^{26,30}$

When pooling these results across the individual studies, we observed that in the subgroup with persisting traction at day 28, a higher proportion of ocriplasmin-treated patients experience a visual function response (49.8\%) compared to control $(29.1 \%, P<0.001)$ (Table 7$)$. This finding indicates that in the subgroup without complete release of adhesion/ traction, ocriplasmin confers visual functioning benefits to patients. 
A

VMA release
B

$\square$ Persisting VMA

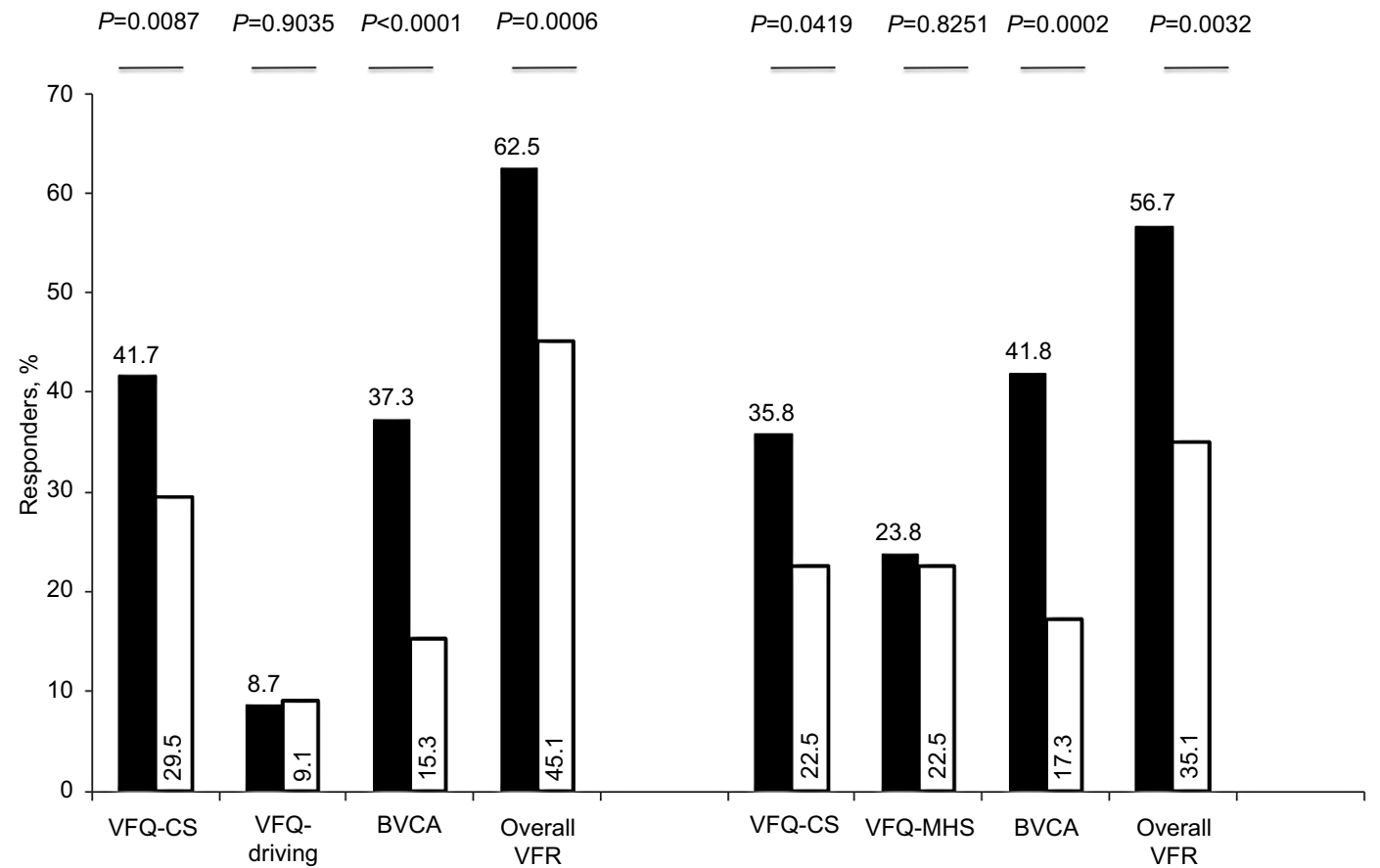

Figure 4 Responder rates for visual function response measures by anatomical outcome (Month 6). (A) MIVI. (B) OASIS.

Abbreviations: BCVA, best corrected visual acuity; VMA, vitreomacular adhesion; VFR, visual function response; VFQ-CS, Visual Function Questionnaire 25-composite score; VFQ-Driving, Visual Function Questionnaire 25-driving subscale; VFQ-MHS, Visual Function Questionnaire 25-mental health subscale.

Table 6 VFR responder analysis by VMA outcome across studies (month six data)

\begin{tabular}{|c|c|c|c|c|}
\hline Response criteria & $\begin{array}{l}\text { VMA release } \\
\%(\mathrm{n} / \mathrm{N})\end{array}$ & $\begin{array}{l}\text { Persisting VMA } \\
\%(n / N)\end{array}$ & $\begin{array}{l}\text { Difference (\%) } \\
(95 \% \mathrm{Cl})^{\mathrm{b}}\end{array}$ & $P$-value ${ }^{c}$ \\
\hline Visual Function Response $\mathrm{e}^{\mathrm{a}}$ & & & & \\
\hline MIVI-TRUST & $62.5(80 / / 28)$ & $45.1(190 / 421)$ & $17.4(7.7,27.0)$ & 0.001 \\
\hline OASIS & $56.7(38 / 67)$ & $35.1(53 / 15 I)$ & $21.6(7.5,35.7)$ & 0.004 \\
\hline Combined & 60.6 & 42.3 & $18.7(10.8,26.7)$ & $<0.001$ \\
\hline
\end{tabular}

Notes: ${ }^{a}$ Response criteria based on overall VFR composed of three dimensions determined by the PCA output (in MIVI-TRUST: VFQ-CS, VFQ-driving, BCVA; in OASIS VFQ-CS, VFQ-MH, BCVA. 'Difference and $\mathrm{Cl}$ between treatment groups are based on the percentage of responses. 'For individual studies, the $P$-value is from Fisher's exact test, comparing VMA release and persisting VMA. For combined studies, pooling of risk differences was based on random effects model using the method of DerSimonian and Laird. ${ }^{28}$ dEstimate based non-stratified treatment effect, not weighted by FTMH strata.

Abbreviations: N, number of subjects in the dataset. n, number of subjects with a success for the endpoint; VFR, visual function response; PCA, principal component analysis; VFQ-CS, Visual Function Questionnaire 25-composite score; VFQ-driving, Visual Function Questionnaire 25-driving subscale; VFQ-MHS, Visual Function Questionnaire 25-mental health subscale; FTMH, full thickness macular hole; MIVI-TRUST, Microplasmin for Intravitreous Injection - Traction Release without Surgical Treatment; OASIS, Ocriplasmin for Treatment for Symptomatic Vitreomacular Adhesion Including Macular Hole.

\section{Discussion}

This review combined PROs from clinical trials of ocriplasmin, given to treat VMT with or without a FTMH. We found that ocriplasmin produces significant patient benefit vs control (sham or placebo-injection) treatment. Ocriplasmin was associated with a higher proportion of patients experiencing a clinically meaningful improvement in visual functioning (11.8\% for VFQ-25 composite score analysis; $23.2 \%$ for VFR responder analysis). The studies were of high quality, being randomized, double-masked, and sham or placebo controlled, with a consequent low risk of bias. Only studies with NEI VFQ-25 were found. A definition of VFR was derived using a principal component analysis which combined VFQ-25 and BCVA. ${ }^{26,30}$ There was no evidence of significant heterogeneity for the pooled PRO outcomes $\left(\mathrm{I}^{2}<50 \%\right)$. However, there were differences in methodological approaches to outcome definitions or in methods for dealing with intercurrent vitrectomy; hence we judged the risk of other bias as unclear. 
A

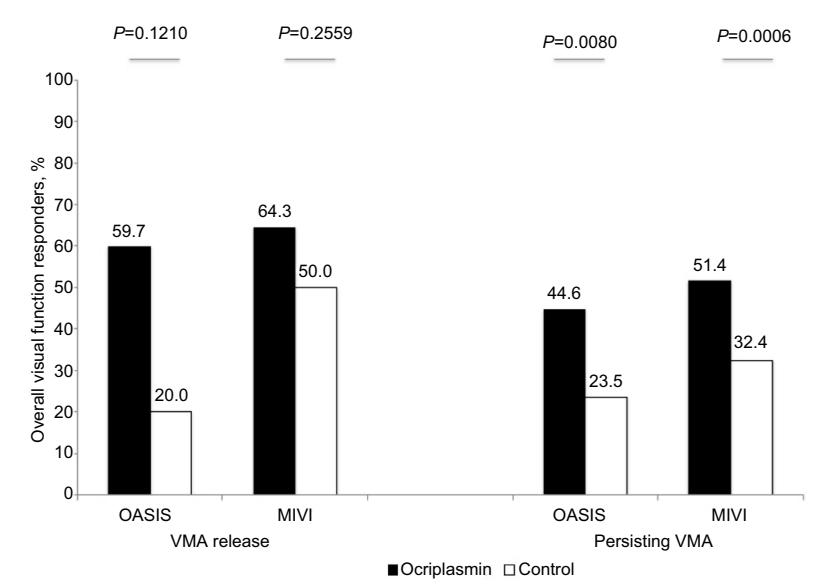

B

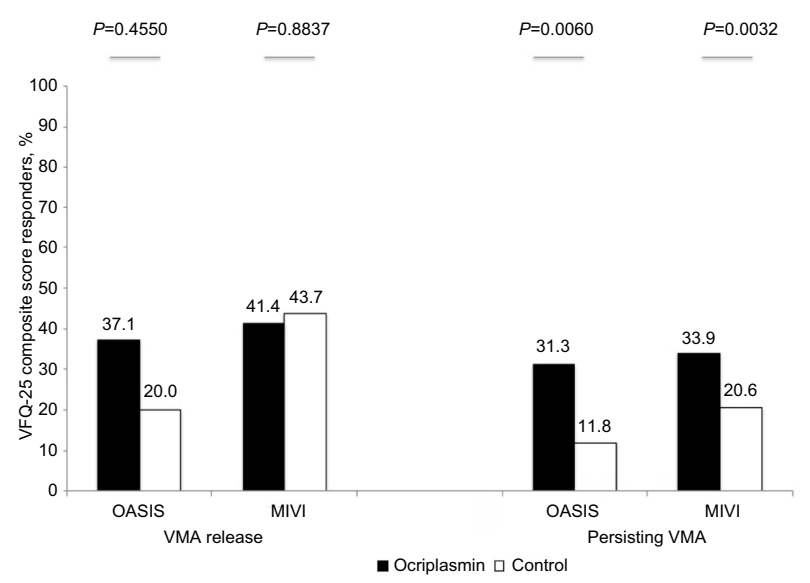

Figure 5 Visual function outcomes by VMA subgroups. (A) Overall visual function response. (B) Visual function composite score. Abbreviations: VMA, vitreomacular adhesion; VFQ-25, Visual Function Questionnaire 25.

Table 7 VFR response at month 6, by VMA status at day 28

\begin{tabular}{|c|c|c|c|c|}
\hline & $\begin{array}{l}\text { Ocriplasmin } \\
\%(n / N)\end{array}$ & $\begin{array}{l}\text { Control } \\
\%(n / N)\end{array}$ & $\begin{array}{l}\text { Difference (\%) } \\
(95 \% \mathrm{Cl})^{\mathrm{b}}\end{array}$ & $P$-value \\
\hline \multicolumn{5}{|l|}{ VMA release at day 28} \\
\hline MIVI-TRUST & $64.3(72 / 1 / 2)$ & $50.0(8 / 16)$ & $\mid 4.3(-|| .8,40.3)$ & 0.283 \\
\hline OASIS & $59.7(37 / 62)$ & $20.0(1 / 5)$ & $39.7(2.6,76.8)$ & 0.158 \\
\hline Combined & 62.7 & 40.2 & $23.5(-8.0,47.8)$ & 0.058 \\
\hline \multicolumn{5}{|l|}{ Persisting VMA at day 28} \\
\hline MIVI-TRUST & $51.4(145 / 282)$ & $32.4(45 / 139)$ & $19.0(9.3,28.8)$ & $<0.001$ \\
\hline OASIS & $44.6(37 / 83)$ & $23.5(16 / 68)$ & $21.0(6.4,35.7)$ & 0.010 \\
\hline Combined & 49.8 & 29.1 & $19.7(11.5-27.8)$ & $<0.001$ \\
\hline
\end{tabular}

Notes: ${ }^{2}$ Response criteria based on overall VFR composed of three dimensions determined by the PCA output (in MIVI-TRUST: VFQ-CS, VFQ-driving, BCVA; in OASIS VFQ-CS, VFQ-MH, BCVA. 'Difference and $\mathrm{Cl}$ between treatment groups are based on the percentage of responses. 'For individual studies, the $P$-value is from Fisher's exact test, comparing control and ocriplasmin. For combined studies, pooling of risk differences was based on random effects model using the method of DerSimonian and Laird. ${ }^{28}$ dEstimate based non-stratified treatment effect, not weighted by FTMH strata.

Abbreviations: $N$, number of subjects in the dataset; $n$, number of subjects with a success for the endpoint; VFR, visual function response; VMA; vitreomacular adhesion; PCA, principal component analysis; VFQ-CS, Visual Function Questionnaire 25-composite score; VFQ-driving, Visual Function Questionnaire 25-driving subscale; VFQ-MHS, Visual Function Questionnaire 25-mental health subscale; FTMH, full thickness macular hole; MIVI-TRUST, Microplasmin for Intravitreous Injection - Traction Release without Surgical Treatment; OASIS, Ocriplasmin for Treatment for Symptomatic Vitreomacular Adhesion Including Macular Hole; BCVA, best corrected visual acuity.

PRO measures provide an opportunity to measure outcomes that resonate with patients, and reveal the patient's perspective on the impact of disease and the value of treatments. Yet, the reality is that the evidence is limited and dominated by VFQ-25 data from the investigational studies. Ongoing observational studies will likely enrich the amount of PRO evidence.

The NEI VFQ-25 is a widely used validated questionnaire used for a range of eye diseases. ${ }^{32,33}$ It is likely to capture patient symptomatology better than a generic measure of health-related QoL tool, such as EuroQol EQ-5D, which instead aims to estimate preferences for a particular health state (health utilities). ${ }^{34,35}$ However, the VFQ-25 is not specifically developed for retinal diseases, and given the symptoms of VMT it would be preferable to also have a validated disease-specific questionnaire..$^{20}$ To examine the influence of VMT on patient functioning, recommendations for future research include the development of new PROs in VMT. This process can be initiated with focus group discussions to appreciate the outcomes that matter to patients with VMT, explore the principal traits of functional vision through a PCA of the VFQ-25 items from all studies, test the psychometric properties of the VFQ-25 through Rasch analysis using both the VFQ-25 and metamorphopsia questionnaires, estimate VFQ-UI utility values, including its psychometric properties.

In the primary ocriplasmin publications, the reported efficacy data focused on anatomical and BCVA outcomes, which is understandable as these are clinically accepted outcome 
measures. Further, release of VMA and nonsurgical closure of macular hole were each associated with improved visual functioning in patients with VMT, as evidenced by favorable outcomes in BCVA and VFQ-25. ${ }^{23,29}$

It is worth noting that patients enrolled in the ocriplasmin investigational studies, compared with observational nondrug studies like the MeMo Study, reported higher QoL impairment in all VFQ-25 subscales except ocular pain (Table S3).${ }^{13}$ In addition, the variability in almost all vision-targeted subscales was larger than in a healthy reference group, suggesting that VMT patients may be more affected in a certain vision domain than others. More specifically, general vision and near distance activities were most impacted, which could be expected as it is consistent with the underlying diagnosis of VMT where not only reduced central visual acuity but also other symptoms such as metamorphopsia or micropsia contribute to morbidity. However, the impact on mental health and role functioning deserves further investigation. ${ }^{36-38}$ These findings underpin the importance to test the psychometric properties of the VFQ-25 in patients with VMT.

Different approaches were taken in the analysis of the PRO endpoints. The visual function responder analysis uses a composite functional endpoint, instead of single VFQ-25 data, and values clinically meaningful improvements the patient experiences in any of the events specified by the components. A composite endpoint has the advantage that it can combine patient-, observer- or clinician-reported measures or that it avoids an arbitrary choice between several important outcomes associated with a patient's disease status (visual acuity, daily functioning, mental health, etc). ${ }^{39}$

Other differences included the analysis approach to vitrectomy. A vitrectomy after initial treatment represents an additional burden to the patient due to the recovery period or long-term risks (cataract development). The occurrence of vitrectomy was assumed a rescue therapy; hence patients requiring a vitrectomy were considered a visual function failure. Thus, the visual function responder analysis integrates patient burden in its PRO construct. The VFQ-25 responder results instead, were analyzed irrespective of vitrectomy outcomes, an approach that impacts the pooled risk difference from $11.8 \%$ (Table 4 ) to $15.2 \%$ (Table S4).

Finally, this review alludes to the caveats with the use of surrogate vs patient-reported endpoints in drug development. In patients who achieved anatomical success, no significant differences in response were observed between ocriplasmin and control for the composite VFR outcome (or VFQ-25 measure), which underlines the relevance of the surrogate endpoint. The analyses by Gandorfer et al and Varma et al also confirmed the importance of achieving an anatomical endpoint (release of traction) on unidimensional functional outcomes (VFQ-25 or BCVA). ${ }^{23,29}$

However, along the same lines a treatment effect was observed in patients who did not experience an anatomical success. This suggests that patients treated with ocriplasmin vs control might still benefit from partial release of traction, so the surrogate endpoint defined as a binary response was unable to capture the functional improvement after treatment. The area of traction is important for therapeutic recommendation; hence the need for a more precise description of the area of traction in eyes with VMT. ${ }^{40}$ The patient's perspective does matter in the quantification of functional benefit.

This review of PROs with ocriplasmin in the treatment of vitreomacular traction followed a protocol which included a comprehensive search strategy using a published search filter, which was expanded by additional terms for disease-specific QoL instruments. Nevertheless, our search resulted in a limited set of publications reporting on PROs. Linking the patient's perspective to NEI VFQ-25 evidence has limitations as it is a broad measure of visual functioning and does not specifically assess some of the visual symptoms commonly experienced by patients with VMT such as the distortion, or micropsia. ${ }^{9,28}$ The VFQ-25 was designed to measure a patients' subjective assessments of visual function, and was validated for persons with vision problems, but not designed for one specific (retinal) vision condition. ${ }^{9,24}$ It has been criticized for floor and ceiling effects, for not being appropriate in certain ophthalmic indications, and for not having been validated in patients with VMT.9,23,24,41,42

When combining the PRO results, we used data from available reports on visual function response. This composite measure comprehensively evaluated changes in vision-related functioning. Applying a PCA, a well-established data reduction technique, the most relevant principal components correlated best with the VFQ-25 composite score in both the MIVITRUST and OASIS datasets. Conversely, the VFQ-25 driving subscale correlated best with the second principal components in the MIVI dataset, while the VFQ-25 mental health subscale correlated best with the second and third principal components in the OASIS dataset. In both datasets, BCVA correlated poorly with either principal components and was therefore considered to add independent information. Due to the use of different definitions in the PRO, heterogeneity (between-study variation in effect) may have been introduced, which can limit the validity of the pooled treatment effect estimate. However, a sensitivity analysis, in which the visual function response was 
based on the two common scores (VFQ-25 composite score and BCVA) generated similar results (Tables S5-S7).

\section{Conclusion}

This review recorded the impairment in visual functioning and vision-related quality of life in patients with VMT. Despite the relatively preserved visual acuity in these patients, the functional burden appears substantial.

The need for a brief multidimensional vision-targeted PRO measure is illustrated by the widespread use of the VFQ25 , nonetheless uncertainty about its sensitivity to visual disability associated with milder forms of VMT remains.

In the absence of an anatomical tool for evaluation of this specific patient population, the randomized studies had included the VFQ-25 as the best available PRO instrument. To examine the influence that VMT disease and interventions have on a patient's day-to-day functioning, recommendations for future research include the development of new PROs in VMT.

Finally, the observation that patients benefit functionally from treatment with ocriplasmin despite absence of resolution of the underlying anatomical condition merits further investigation to assess which endpoints in future trials may help more accurately quantify and compare the functional benefits of different treatment options.

\section{Data availability}

The database with data extraction and analyses can be obtained upon request.

\section{Acknowledgments}

The authors should like to thank the research team members of Dr Mangione, Ronald Hays and Karen Spritzer for retrieving the datasets and calculating the composite scores; Luc Duchateau and Thomas Verstraeten who previously collaborated with BL and TJ on the development of the Visual Function Response measure. No funding was provided for the review and synthesis of the PRO literature. Approval was sought and obtained from Oxurion NV to use selected PRO data from clinical study reports.

\section{Author contributions}

All authors contributed to data analysis, drafting or revising the article, gave final approval of the version to be published, and agree to be accountable for all aspects of the work.

\section{Disclosure}

No commercial organization had any role in the design, conduct or financing of this study. BL and $\mathrm{KB}$ provide medical and health economic consulting services to several biopharmaceutical companies, including Oxurion NV and Santen Inc. The authors report no other conflicts of interest in this work.

\section{References}

1. Duker JS, Kaiser PK, Binder S, et al. The International Vitreomacular Traction Study Group classification of vitreomacular adhesion, traction, and macular hole. Ophthalmology. 2013;120(12):2611-2619.

2. Jackson TL, Donachie PH, Johnston RL; Vitreomacular Traction Study Group. Electronic medical record database study of vitrectomy and observation for vitreomacular traction. Retina. 2016;36(10): 1897-1905.

3. Bottós JM, Elizalde J, Rodrigues EB, Maia M. Current concepts in vitreomacular traction syndrome. Curr Opin Ophthalmol. 2012;23(3):195-201.

4. Jackson TL, Regillo CD, Girach A, Dugel PU; MIVI-TRUST Study Group. Baseline predictors of vitreomacular adhesion/traction resolution following an intravitreal injection of ocriplasmin. Ophthalmic Surg Lasers Imaging Retina. 2016;47(8):716-723.

5. Denniston AK, Kyte D, Calvert M, Burr JM. An introduction to patient-reported outcome measures in ophthalmic research. Eye. 2014;28(6):637-645.

6. Johnson MW. Posterior vitreous detachment: evolution and complications of its early stages. Am J Ophthalmol. 2010;149(3):371-382.e1.

7. Tanner V, Chauhan DS, Jackson TL, Williamson TH. Optical coherence tomography of the vitreoretinal interface in macular hole formation. $\mathrm{Br}$ J Ophthalmol. 2001;85(9):1092-1097.

8. Chauhan DS, Antcliff RJ, Rai PA, Williamson TH, Marshall J. Papillofoveal traction in macular hole formation: the role of optical coherence tomography. Arch Ophthalmol. 2000;118(1):32-38.

9. Wickström K, Moseley J. Biomarkers and surrogate endpoints in drug development: a European regulatory view. Invest Ophthalmol Vis Sci. 2017;58(6):BIO27-BIO33.

10. Jackson TL, Nicod E, Simpson A, Angelis A, Grimaccia F, Kanavos P. Symptomatic vitreomacular adhesion. Retina. 2013;33(8):1503-1511.

11. Stalmans P, Benz MS, Gandorfer A, et al. Enzymatic vitreolysis with ocriplasmin for vitreomacular traction and macular holes. $N$ Engl J Med. 2012;367(7):606-615.

12. Dugel PU, Tolentino M, Feiner L, Kozma P, Leroy A. Results of the 2-year ocriplasmin for treatment for symptomatic vitreomacular adhesion including macular hole (OASIS) randomized trial. Ophthalmology. 2016;123(10):2232-2247.

13. Patel PJ, Steel DH, Hirneiß C, et al. Patient-reported prevalence of metamorphopsia and predictors of vision-related quality of life in vitreomacular traction: a prospective, multi-centre study. Eye. 2018;120.

14. Neffendorf JE, Simpson ARH, Steel DHW, et al. Intravitreal gas for symptomatic vitreomacular adhesion: a synthesis of the literature. Acta Ophthalmol. 2018;96(7):685-691.

15. American Academy of Ophthalmology Retina/Vitreous Panel. Preferred Practice Pattern ${ }^{\circledR}$ Guidelines. Idiopathic macular hole. San Francisco, CA: American Academy of Ophthalmology; 2014 [updated 2017]: 1-33. Available from: www.aao.org/ppp. Accessed October 3, 2018.

16. Neffendorf JE, Kirthi V, Pringle E, Jackson TL. Ocriplasmin for symptomatic vitreomacular adhesion. Cochrane Database Syst Rev. 2017;10: CD011874.

17. NICE. Guide to the methods of technology appraisal 2013; 2013:1-102. https://www.nice.org.uk/process/pmg9/chapter/foreword\#.XHLCLhwmi6I.email.

18. Folk JC, Adelman RA, Flaxel CJ, Hyman L, Pulido JS, Olsen TW. Idiopathic Epiretinal Membrane and Vitreomacular Traction Preferred Practice Pattern ${ }^{\circledR}$ Guidelines. Ophthalmology. 2016;123(1):P152-P181.

19. US Department of Health and Human Services Food and Drug Administration. Guidance for industry. 2009:1-43.

20. Prem Senthil M, Khadka J, Pesudovs K. Assessment of patient-reported outcomes in retinal diseases: a systematic review. Surv Ophthalmol. 2017;62(4):546-582. 
21. Paisley S, Booth A, Mensinkai S. Health-related quality of life studies. Etext on Health Technology Assessment (HTA) information resources. Bethesda, MD: US National Library of Medicine (NLM), National Information Center on Health Services Research and Healthcare Technology (NICHSR), 2005.

22. Ara R, Brazier J, Peasgood T, Paisley S. The identification, review and synthesis of health state utility values from the literature. Pharmacoeconomics. 2017;35(Suppl 1):43-55.

23. Gandorfer A, Benz MS, Haller JA, et al. Association between anatomical resolution and functional outcomes in the MIVI-TRUST studies using ocriplasmin to treat symptomatic vitreomacular adhesion/vitreomacular traction, including when associated with macular hole. Retina. 2015;35(6):1151-1157.

24. Mangione CM, Lee PP, Gutierrez PR, et al. Development of the 25-list-item National Eye Institute visual function questionnaire. Arch Ophthalmol. 2001;119(7):1050-1058.

25. RAND C. The National Eye Institute 25 -item visual function questionnaire (VFQ-25). 2000:1-15. Available from: https://www.rand.org/ health-care/surveys_tools/vfq.html. Accessed October 3, 2018.

26. Jackson TL, Verstraeten T, Duchateau L, Lescrauwaet B. Visual function response to ocriplasmin for the treatment of vitreomacular traction and macular hole. Acta Ophthalmol. 2017;95(8):e740-e745.

27. Jolliffe I. Principal Component Analysis. Chichester, UK: John Wiley \& Sons, Ltd; 2014.

28. DerSimonian R, Laird N. Meta-analysis in clinical trials. Control Clin Trials. 1986;7(3):177-188.

29. Varma R, Haller JA, Kaiser PK. Improvement in patient-reported visual function after Ocriplasmin for Vitreomacular adhesion: results of the microplasmin for intravitreous injection-traction release without surgical treatment (MIVI-TRUST) trials. JAMA Ophthalmol. 2015;133(9):997-1004.

30. Lescrauwaet B, Duchateau L, Verstraeten T, Jackson TL. Visual function response to ocriplasmin for the treatment of vitreomacular traction and macular hole: the OASIS study. Invest Ophthalmol Vis Sci. 2017;58(13):5842-5848.

31. Guyatt GH, Thorlund K, Oxman AD, Gg H, et al. Grade guidelines: 13. Preparing summary of findings tables and evidence profiles-continuous outcomes. J Clin Epidemiol. 2013;66(2):173-183.
32. Dean S, Mathers JM, Calvert M, et al. "The patient is speaking": discovering the patient voice in ophthalmology. Br J Ophthalmol. 2017;101(6):700-708.

33. Wickström K, Moseley J. Biomarkers and surrogate endpoints in drug development: a European regulatory view. Invest Ophthalmol Vis Sci. 2017;58(6):BIO27-BIO33.

34. Longworth L, Yang Y, Young T, et al. Use of generic and conditionspecific measures of health-related quality of life in NICE decisionmaking: a systematic review, statistical modelling and survey. Health Technol Assess. 2014;18(9):1-224.

35. Tosh J, Brazier J, Evans P, Longworth L. A review of generic preferencebased measures of health-related quality of life in visual disorders. Value Health. 2012;15(1):118-127.

36. Naik RK, Gries KS, Rentz AM, Kowalski JW, Revicki DA. Psychometric evaluation of the National Eye Institute visual function questionnaire and visual function questionnaire utility index in patients with non-infectious intermediate and posterior uveitis. Qual Life Res. 2013;22(10):2801-2808.

37. Frick KD, Drye LT, Kempen JH, et al. Associations among visual acuity and vision- and health-related quality of life among patients in the multicenter uveitis steroid treatment trial. Invest Ophthalmol Vis Sci. 2012;53(3):1169-1176.

38. Lundström M, Wendel E. Assessment of vision-related quality of life measures in ophthalmic conditions. Expert Rev Pharmacoecon Outcomes Res. 2006;6(6):691-724.

39. Patrick DL, Burke LB, Powers JH, et al. Patient-reported outcomes to support medical product labeling claims: FDA perspective. Value Health. 2007;10(Suppl 2):S125-S137.

40. Paul C, Krug P, Müller HH, et al. Comparison of the horizontal diameter to a modeled area of traction in eyes with vitreomacular traction: is the diameter close enough to the truth? Graefes Arch Clin Exp Ophthalmol. 2018;256(10): 1817-1822

41. Pesudovs K, Gothwal VK, Wright T, Lamoureux EL. Remediating serious flaws in the National Eye Institute visual function questionnaire. $J$ Cataract Refract Surg. 2010;36(5):718-732.

42. Dougherty BE, Bullimore MA. Comparison of scoring approaches for the NEI VFQ-25 in low vision. Optom Vis Sci. 2010;87(8): 543-548.
Patient Related Outcome Measures

\section{Publish your work in this journal}

Patient Related Outcome Measures is an international, peer-reviewed, open access journal focusing on treatment outcomes specifically relevant to patients. All aspects of patient care are addressed within the journal and practitioners from all disciplines are invited to submit their work as well as healthcare researchers and patient support groups.
Dovepress

The journal is included in PubMed. The manuscript management system is completely online and includes a very quick and fair peer-review system. Visit http://www.dovepress.com/testimonials.php to read real quotes from published authors. 